\title{
ARTIGOS
}

\section{REPRESENTACIÓN DE NIÑAS Y NIÑOS EN IMÁGENES DE JUGUETES: ¿EL COMIENZO DEL CAMBIO?}

MYRIAM ALVARIÑAS-VILLAVERDE' CRISTINA LÓPEZ-VILLAR"

\section{RESUMEN}

Este trabajo estudia las imágenes en catálogos de juguetes infantiles, observando las diferencias de representación de niñas y niños en función del producto. La muestra es de 2.223 imágenes relativas a los períodos navideños de 2012 y 2015. La transmisión de estereotipos sigue vigente. Sin embargo, en algunas categorías de juguetes considerados clásicamente como masculinos o femeninos, se aprecian cambios interesantes, de forma que su representación no es tan exclusiva. Se observa, además, un importante incremento de imágenes mixtas, en las que niñas y niños comparten actividades. En este sentido, la variación más llamativa se da en la categoría de tareas domésticas. Así y todo, se hace hincapié en que este tipo de mensajes ha de ir más allá de la exposición de imágenes mixtas.

PUBLICIDAD • INFANCIA • ESTEREOTIPO • JUGUETES

\section{REPRESENTATION OF BOYS AND GIRLS IN IMAGES OF TOYS: THE BEGINNING OF A CHANGE?}

\section{ABSTRACT}

This paper studies the images in children's toy catalogs, observing the differences in the representation of boys and girls according to the product. The sample includes 2,223 images corresponding to the periods of Christmas in 2012 and 2015. The dissemination of stereotypes is still in force. However, in some categories of toys considered classically as masculine or feminine, interesting changes are observed which show that their representation is no longer so exclusive. There is also an important increase of mixed images, in which girls and boys share

Universidade de Vigo, Pontevedra, Espanha; myalva@uvigo.es

II activities. In this sense, the most obvious variation is in the category of household chores. However, it should be noted that this type of message should go beyond the exhibition of mixed images.

PUBLICITY • CHILDHOOD • STEREOTYPE ・ TOYS 
Ce travail étudie les images de catalogues de jouets pour observer les différences entre la représentation des garçons et celle des filles en fonction des articles. L'échantillon, de 2.223 images, se référant aux périodes de Noël de 2012 et 2015, démontre que la transmission des stéréotypes persiste. Toutefois, pour certaines catégories de jouets considérés traditionnellement comme masculins ou féminins des changements intéressants indiquant que leur représentation n'est plus aussi exclusive qu'auparavant sont à noter. Une augmentation importante d'images mixtes sur lesquelles garçons et filles partagent des activités a été verifiée la variation la plus évidente concerne la catégorie des travaux domestiques. Cependant, il faut souligner que ce type de messages devrait aller au-delà de l'exposition d'images mixtes.

PUBLICITÉ • ENFANCE • STÉRÉOTYPE • JOUETS

\section{REPRESENTAÇÃO DE MENINAS E MENINOS EM IMAGENS DE BRINQUEDOS: O COMEÇO DA MUDANÇA?}

RESUMO

Este trabalho estuda as imagens em catálogos de brinquedos infantis, observando as diferenças de representação de meninas e meninas em função do produto. A mostra é de 2.223 imagens correspondentes aos perídos natalinos de 2012 e 2015. A transmissão de estereótipos continua vigente. No entanto, em algumas categorias de brinquedos considerados classicamente como masculinos ou femininos, são observadas mudanças interessantes, mostrando que sua representação já não é tão exclusiva. Verifica-se também um importante aumento de imagens mistas, nas quais meninas e meninos compartilham atividades. Nesse sentido, a variação mais evidente ocorre na categoria das tarefas domésticas. Entretanto, ressalta-se que esse tipo de mensagens deve ir além da exposição de imagens mistas. 


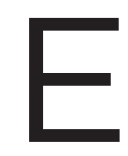

L PÚBLICO INFANTIL SE HA IDO SITUANDO CADA VEZ CON MÁS FUERZA EN EL MARCO DE consumidores de bienes y servicios, apareciendo como mercado (BRINGUÉ; DE LOS ÁNGELES, 2000). Además, la investigación social ha demostrado que persiste una cultura de consumo diferenciada en función del género (STEINBERG; KINCHELOE, 1997). Las expectativas sociales llevan a las personas adultas a elegir juguetes basándose en estereotipos; una constatación clara de ello es el hallazgo de que el primer juguete que se recibe en la niñez es un reflejo de estos estereotipos (FISHER-THOMPSON, 1990; FISHER-THOMPSON; SAUSA; WRIGHT, 1995; CUGMAS, 2010).

Hace casi 40 años, Rheingold y Cook (1975) analizaron los juguetes presentes en las habitaciones infantiles. Los niños poseían mayor variedad de juguetes y muchos más vehículos. Ellos también tenían más juguetes para el desarrollo de capacidades espaciotemporales o equipamientos deportivos, máquinas, juegos bélicos, educativos o artísticos. Asimismo, sus muñecos eran soldados o vaqueros (BLAKEMORE; CENTERS, 2005). En las habitaciones de las niñas se veían más muñecas, casas de muñecas y aparatos domésticos como lavadoras o lavavajillas (POMERLEAU et al., 1990).

Después de este estudio pionero, otros han tratado el tema de la tipología de juguetes y su relación con cuestiones de género. Así, algunos trabajos se basan en las respuestas de progenitores acerca de primeros juguetes o juguetes favoritos de sus hijas/os (CUGMAS, 2010; 
FRANCIS, 2010). En otras ocasiones es el niño/a quien se manifiesta sobre sus predilecciones (CHERNEY; LONDON, 2006). También se recurre a la observación del juego libre (CHERNEY; DEMPSEY, 2010; CHERNEY et al., 2003; TODD; BARRY; THOMMESSEN, 2016) para describir los usos y preferencias de juguetes en niñas y niños. Otro interesante corpus de trabajos se centra en el análisis de imágenes en tiendas online (AUSTER; MANSBACH, 2012) o en televisión (CONSEJO AUDIOVISUAL DE ANDALUCÍA, 2009; FERRER, 2007; KAHLENBERG; HEIN, 2010; MARTÍNEZ-PASTOR; NICOLÁS; SALAS, 2013; PÉREZ-UGENA; MARTÍNEZPASTOR; SALAS, 2011) tomando la mayoría de ellos como período de estudio las navidades, debido a la abundante publicidad destinada al público infantil que se emite en esta época. Las cartas enviadas a Papá Noel también son objeto de estudio en este sentido (DOWNS, 1983; MARCON; FREEMAN, 1996; PINE; WILSON; NASH, 2007).

Alrededor de los dieciocho meses se pueden observar diferencias de sexo en la elección de juguetes (JADVA; HINES; GOLOMBOK, 2010), aunque para Tobin et al. (2010) es en torno a los tres años cuando se toma consciencia de ello. Podemos apreciar en los de ellas asociaciones con tareas del hogar, los cuidados, la maternidad o la estética y en los de ellos vínculos con valores como la competición, la acción, la tecnología, la agresividad, el poder, la fuerza o las habilidades para la construcción (AUSTER; MANSBACH, 2012; ESPINAR, 2007; FRANCIS, 2010; MARTÍNEZ-PASTOR; NICOLÁS; SALAS, 2013; PÉREZ-UGENA; MARTÍNEZ-PASTOR; SALAS, 2011). Por tanto, es fácilmente entendible que el uso de unos u otros juguetes influencie ya desde las primeras edades el desarrollo cognitivo, emocional y comportamental. Zegaï (2010) lo expresa diciendo que a través del microcosmos que se crea al interactuar con los juguetes (con personajes, objetos, reglas y actividades) estos funcionan como una primera iniciación de las niñas y niños a muchos campos de la vida social, tales como la maternidad, la mecánica o la postura del cuerpo.

Pese a la influencia que puedan tener los medios en la socialización en la infancia, no se debe perder de vista el enfoque interpretativo (CORSARO, 1993, 2005) que la observa como algo reproductivo y no lineal. Niñas y niños internalizan la cultura adulta, pero son además sujetos activos que contribuyen a su desarrollo.

Los juguetes tipificados como femeninos o masculinos coexisten con otros que no poseen atributos que hagan suponer que el juguete es para un sexo u otro: son los juguetes neutros. Cherney y Dempsey (2010) utilizan la categoría de juguete ambiguo para referirse a aquellos que poseen características asociadas a ambos sexos. Por su parte, MorinMessabel et al. (2016) consideran esta denominación cuando el juguete puede estar representado por una niña o por un niño indistintamente. En esta esfera más neutral se han situado históricamente los juguetes 
educativos, artísticos, musicales, de manipulación o creativos, aunque hay variaciones entre estudios (AUSTER; MANSBACH, 2012; BLAKEMORE; CENTERS, 2005; CHERNEY; LONDON, 2006; MILLER, 1987).

Últimamente se han puesto en marcha propuestas basadas en la pedagogía de la igualdad en Suecia, tal como explican MartínezReina y Vélez (2008), que restringen el uso de juguetes fuertemente estereotipados, con resultados muy positivos en la conducta de niños y niñas. También, campañas como Let toys be toys han puesto de relieve la importancia de ofrecer juguetes desvinculándolos del estigma de género para favorecer el proceso educativo.

Desde hace años, se está reivindicando también la necesidad de aportar mensajes menos sexistas a través de los juguetes en los medios de comunicación (LÓPEZ-VILLAR, 2013; MARTÍNEZ-PASTOR; NICOLÁS; SALAS, 2013; PEREIRA, 2009; PÉREZ-UGENA; MARTÍNEZ-PASTOR; SALAS, 2011). Estos medios son agentes de educación social y transmiten cultura (PINO-JUSTE, 2000); por tanto, sus contenidos pueden suponer un importante recurso para desarrollarse en igualdad.

En concreto, existe una preocupación respecto a la publicidad emitida y su falta de cumplimiento de la legislación vigente (CONSEJO AUDIOVISUAL DE ANDALUCÍA, 2009; FERRER, 2007; MARTÍNEZREINA; VÉLEZ, 2008) por la repercusión tan importante que tiene en la educación en valores en la infancia.

En este sentido, en España, varias leyes establecen medidas relacionadas con el contexto publicitario. La Ley Orgánica 3/2007, de 22 de marzo, para la igualdad efectiva de mujeres y hombres, destaca que la publicidad dirigida a menores debe transmitir una imagen no estereotipada. También la Ley Orgánica 1/2004, de 28 de diciembre, de medidas de protección integral contra la violencia de género o la Ley 34/1988, de 11 de noviembre, general de la publicidad, y su modificación en 2014, establecen argumentos similares relativos al fomento del principio de igualdad de géneros. En la misma línea se manifiesta la Asociación Española de Fabricantes de Juguetes al presentar en 2010 un Código de Autorregulación específico.

En Suiza, un país preocupado por la equidad de género, un estudio analiza las colecciones de juguetes (NELSON, 2005). Se pretendía observar si existían diferencias respecto a otros países. El estudio constata que estos eran categorizados en función del sexo igualmente. Este hecho cambia ante la denuncia, en 2008, de un grupo de estudiantes ante el Observatorio Sueco de la Publicidad respecto a la empresa Toys R Us. Como consecuencia, la empresa modifica su catálogo de juguetes para mostrar a niños y niñas jugando a la vez con diferentes productos que antes eran anunciados para uno u otro sexo. En España, hay que esperar hasta las navidades de 2014 para que una empresa de juguetes decida 
romper con estereotipos sexistas y muestre a niñas utilizando grúas o jugando al futbolín y a niños usando lavadoras o cuidando bebés.

Si bien la televisión ha sido un medio bastante estudiado, el análisis de catálogos de juguetes infantiles es una temática poco abordada hasta el momento. Martínez-Reina y Vélez (2008) utilizan este recurso para su investigación. Los sujetos participantes señalan imágenes de juguetes a partir de una pregunta específica. Se constata que de 35 juguetes evaluados solo tres se reconocen en mayor proporción como neutros. Asimismo, se evidencia una clara tendencia a relacionar los juguetes con el propio sexo. En otra investigación más reciente (MORINMESSABEL et al., 2016) se utiliza también este tipo de imágenes para que el alumnado categorice los juguetes como de niñas, de niños, ambiguos o educativos. Se concluye que las categorizaciones se rigen por criterios estereotipados y que esta persistencia es preocupante porque los estereotipos son herramientas de legitimización de las desigualdades sociales.

Pereira (2009) estudia catálogos de juguetes en 2006 y 2007 analizando la representación publicitaria desde la perspectiva de género. Su pretensión es detectar aquellos mensajes discriminatorios que, directa o indirectamente, se dirigen a la infancia y para ello investigan el texto, la imagen y el color. En este caso, también se determina que muchos ofrecen una interpretación de la realidad colmada de estereotipos y reproduciendo los valores del orden patriarcal.

Consideramos que es preciso ampliar la base científica en relación con este tema y conocer si en la actualidad se va atisbando algún tipo de cambio. Siguiendo la línea de Pereira, nos hemos propuesto analizar las imágenes de juguetes en catálogos publicitarios posteriores, observando las diferencias de representación de niños y niñas en cada categoría de juguete. Concretamente, se han escogido catálogos de los períodos navideños de 2012 y 2015 para comprobar si ha habido una evolución en algún parámetro, a partir de la presencia en 2014 de un catálogo en España que rompió con los estereotipos sobre feminidades y masculidades.

\section{METODOLOGÍA MUESTRA}

Se realiza un muestreo intencionado de 12 catálogos publicitarios distribuidos en España en formato pdf o papel. De ellos, tres son de multinacionales que venden todo tipo de productos y nueve de empresas especializadas en juguetes. El número total de páginas revisadas es de 4009. La muestra está constituida por 2223 imágenes, 1126 (50.7\%) relativas a 2012 y 1097 (49.3\%) a 2015. 


\section{INSTRUMENTO}

Se utilizó una hoja de registro que permitía recoger información de carácter cuantitativo y cualitativo. Los apartados de la ficha de análisis fueron: nombre del catálogo, nombre del juguete, página, foto del juguete, sexo (solo femenino, solo masculino o ambos), categoría (tipo) de juguete, número de niños/niñas/ambos (se registra cuántos niños y cuántas niñas hay en la imagen), número de personas adultas (se registra cuántos hombres y cuántas mujeres hay en la imagen) y observaciones. Este último apartado permitió obtener datos que pasarían inadvertidos en el análisis cuantitativo, como los roles de género en un mismo juguete o el color de la página y de los productos mostrados. La categoría del juguete, exhaustiva y excluyente, se elige a partir de una clasificación que define cada tipo (ver Cuadro 1). En este artículo nos centraremos en el estudio de tres variables: año, sexo y categoría del juguete. 


\section{CUADRO 1}

\section{DEFINICIÓN DE CATEGORÍAS DE JUGUETES}

\begin{tabular}{|c|c|}
\hline Aire libre & $\begin{array}{l}\text { Juguetes típicos de jardín y que se usan en actividades de aire libre como columpios, } \\
\text { toboganes o tiendas de campaña. }\end{array}$ \\
\hline Bélicos & $\begin{array}{l}\text { Juguetes que reproducen actos de violencia o guerra como escopetas, pistolas o } \\
\text { espadas. }\end{array}$ \\
\hline Científicos & $\begin{array}{l}\text { Juegos y juguetes de astronomía, química o relacionados con la naturaleza como } \\
\text { microscopios, tubos de ensayo o lupas. }\end{array}$ \\
\hline Construcción & $\begin{array}{l}\text { Juguetes que reproducen elementos usados en la construcción o que permiten } \\
\text { construir objetos a través de piezas como herramientas o legos. }\end{array}$ \\
\hline Deportes & $\begin{array}{l}\text { Juguetes que permiten realizar actividad física o deportes como balones o material de } \\
\text { malabares. }\end{array}$ \\
\hline Estética & $\begin{array}{l}\text { Juguetes que reproducen elementos de estética de personas adultas y que no se } \\
\text { relacionan con una profesión, como accesorios de joyería o maletín de maquillaje. }\end{array}$ \\
\hline Figuras de acción & $\begin{array}{l}\text { Muñecas/os representados por superhéroes, animales o marionetas, diseñados para } \\
\text { jugar con ellos en acción, no para ser cuidados. Por ejemplo: figura de Superman o } \\
\text { marioneta de los tres cerditos. }\end{array}$ \\
\hline $\begin{array}{l}\text { Juegos de interior } \\
\text { activos }\end{array}$ & $\begin{array}{l}\text { Juegos o juguetes que se realizan en el interior pero que implican actividad física, como } \\
\text { juego de enredos o alfombra de baile. }\end{array}$ \\
\hline Juegos de mesa & $\begin{array}{l}\text { Cualquier juego de mesa realizado tanto sobre una mesa como sobre el suelo, pero que } \\
\text { no implica esfuerzo físico importante, como puzzles o ajedrez. }\end{array}$ \\
\hline Manualidades y arte & $\begin{array}{l}\text { Actividades de motricidad fina que suponen el desarrollo de la creatividad, salvo las } \\
\text { referidas a cuestiones estéticas, que se incluyen en el apartado denominado estética. } \\
\text { Por ejemplo: juego para pintar o para elaborar figuras de barro. }\end{array}$ \\
\hline Medio de locomoción & $\begin{array}{l}\text { Juguetes que permiten el desplazamiento. No se incluyen las motos, bicicletas, etc. } \\
\text { de juguete que no permiten el desplazamiento de niños y niñas sobre ellos y solo su } \\
\text { manipulación. Por ejemplo: bicicletas, motos o patinetes. }\end{array}$ \\
\hline $\begin{array}{l}\text { Muñecas/os, peluches y } \\
\text { accesorios }\end{array}$ & $\begin{array}{l}\text { Reproducciones de bebés, niñas/os o animales que se diferencian normalmente de las } \\
\text { figuras de acción por su tamaño y el material del que están elaboradas. Se incluyen } \\
\text { en esta categoría los complementos que acompañan a muñecas/os y que se pueden } \\
\text { considerar accesorios de cuidados, así como las casas de muñecas. Por ejemplo: recién } \\
\text { nacido de Nenuco o cuna de muñeca. }\end{array}$ \\
\hline Musicales & $\begin{array}{l}\text { Juguetes que representan instrumentos musicales o elementos relacionados con la } \\
\text { música, como pianos, guitarras o micrófonos. }\end{array}$ \\
\hline Nuevas tecnologías & $\begin{array}{l}\text { Artilugios relacionados con la electrónica o informática, como consolas, tablets o } \\
\text { cámaras fotográficas. }\end{array}$ \\
\hline Objetos cotidianos & $\begin{array}{l}\text { Juguetes que representan objetos de uso común en el día a día y que no pueden } \\
\text { incluirse en el resto de categorías, como mochilas o teléfonos. }\end{array}$ \\
\hline Oficios & $\begin{array}{l}\text { Juguetes en los que tanto la imagen del niño o niña como el juguete en sí se identifican } \\
\text { con una profesión de la vida real. Por ejemplo: taller de carpintería o cocina de chef. }\end{array}$ \\
\hline Tareas domésticas & $\begin{array}{l}\text { Juguetes que permiten realizar actividades de casa, como limpiar o cocinar, o fuera de } \\
\text { ella pero vinculadas a las tareas del hogar, como hacer la compra. }\end{array}$ \\
\hline Transporte & $\begin{array}{l}\text { Medio de transporte representado en un juguete o accesorios como coches, trenes, } \\
\text { aviones u otro tipo de medios asociados como scalextrics o garajes. }\end{array}$ \\
\hline
\end{tabular}

Fuente: Elaboración propia.

\section{PROCEDIMIENTO}

Las imágenes se seleccionaban ante la aparición de una fotografía que mostraba a un sujeto que fuese niño o niña, tanto si lo hacían en solitario como en compañía de una persona adulta; por eso, los dibujos se descartaron. También se prescindió de las imágenes de bebés, ya que a veces resultaba imposible descifrar si la foto que se veía correspondía a una niña o a un niño. Asimismo, se excluyeron las prendas de vestir, libros, muebles y embalajes de juguetes. 
Para validar el instrumento se recurrió al juicio de nueve personas doctoras y expertas en análisis de contenido. Mediante una prueba piloto se entrenó a tres sujetos codificadores. Se realizaron tres sesiones de una hora, utilizando catálogos que no se incluyeron en la muestra definitiva. Finalmente, cada persona analizó un catálogo para calcular el grado de acuerdo intercodificador/a. El índice Kappa de Cohen resultó de alta fiabilidad (>.91) para todas las categorías. Tras esta prueba, todas las personas que codificaban analizaron todos los catálogos de la muestra. El índice Kappa de Cohen se calculó de nuevo, obteniéndose una fiabilidad $>.87$.

\section{RESULTADOS \\ RESULTADOS DE LOS DATOS CUANTITATIVOS}

Los resultados confirman que existe una mayor presencia de anuncios con participación única de niños (44.4\%). siendo mínima la variación entre un año y otro (de un 4\% aproximadamente). En segundo lugar aparecen los anuncios destinados solo a las niñas (un 36.3\% del total) pero con un notable descenso del 12\% desde el año 2012 al 2015, que se corresponde con un incremento de un $16 \%$ en los anuncios con representación mixta. Esta variación ha resultado ser altamente significativa para $\mathrm{p}<.001$ según se deriva de la existencia de asociación en el test Chi-cuadrado.

Si nos centramos en la variación en el porcentaje exclusivo de niños en los anuncios, podemos apreciar que solamente en dos tipos no ha habido cambios significativos ( $\mathrm{p}>.05$ ): bélicos y construcción. En el resto de categorías esos cambios sí que han sido significativos. Se observan claros incrementos en 2015 ( $\mathrm{p}<.001$ ) en los juguetes de los tipos: deportes (30.3\%), musicales (26.3\%), juegos de interior activos $(24.9 \%)$ y oficios (22.9\%) principalmente. Frente a esto, se ha encontrado un claro descenso, también altamente significativo en los tipos: manualidades/arte (-24.6\%), transporte (-23.8\%), y juegos de mesa (-20.9\%).

Si nos fijamos en las variaciones porcentuales mayores del 10\% entre ambos períodos de estudio (resaltados en negrita en las tablas), observamos menos cantidad de descensos que en la representación de niñas. 
TABLA 1

ANÁLISIS COMPARATIVO DE LA PRESENCIA DEL GÉNERO MASCULINO EN CADA TIPO DE JUGUETE

\begin{tabular}{|c|c|c|c|c|c|}
\hline \multirow{2}{*}{ TIPO } & \multicolumn{2}{|c|}{ \% NIÑOS / AÑO } & \multirow{2}{*}{$\begin{array}{l}\text { VARIACIÓN } \\
\text { PORCENTUAL }\end{array}$} & \multicolumn{2}{|c|}{ TEST BINOMIAL } \\
\hline & 2012 & 2015 & & VALOR & $p$ \\
\hline Aire libre & $11.5 \%$ (3) & $6.1 \%(3)$ & $-5.4 \%$ & 2.38 & $.019^{*}$ \\
\hline Bélicos & $95.8 \%(23)$ & $93.8 \%(15)$ & $-2.0 \%$ & 1.42 & .158 \\
\hline Científicos & $60.0 \%(15)$ & $46.8 \%(22)$ & $-13.2 \%$ & 3.88 & $<.000^{* *}$ \\
\hline Construcción & $68.2 \%(15)$ & $65.9 \%(54)$ & $-2.3 \%$ & 1.53 & .130 \\
\hline Deportes & $21.4 \%(3)$ & $51.7 \%(15)$ & $30.3 \%$ & 6.56 & $<.000^{* *}$ \\
\hline Estética & 0 & $4.0 \%(1)$ & $4.0 \%$ & 2,03 & $.045 *$ \\
\hline Figuras acción & $60.0 \%(15)$ & $65.0 \%(26)$ & $5.0 \%$ & 2.28 & $.025 *$ \\
\hline $\begin{array}{l}\text { Juegos de interior } \\
\text { activos }\end{array}$ & $36.7 \%(11)$ & $61.6 \%(45)$ & $24.9 \%$ & 5.73 & $<.000^{* *}$ \\
\hline Juegos de mesa & $32.8 \%(22)$ & $11.9 \%$ (7) & $-20.9 \%$ & 5.12 & $<.000^{* *}$ \\
\hline Manualidades/arte & $33.7 \%(30)$ & $9.1 \%(2)$ & $-24.6 \%$ & 5.68 & $<.000^{* *}$ \\
\hline $\begin{array}{l}\text { Medios de } \\
\text { locomoción }\end{array}$ & $70.8 \%$ (189) & $55.1 \%(129)$ & $-15.7 \%$ & 4.29 & $<.000^{* *}$ \\
\hline Muñecas/peluches & $2.5 \%(4)$ & $11.6 \%(15)$ & $9.1 \%$ & 3.15 & $.002^{* *}$ \\
\hline Musicales & $37.8 \%(14)$ & $64.1 \%(25)$ & $26.3 \%$ & 5.94 & $<.000^{* *}$ \\
\hline Nuevas tecnologías & $48.6 \%(18)$ & $33.3 \%(2)$ & $-15.3 \%$ & 4.23 & $<.000^{* *}$ \\
\hline Objetos cotidianos & $7,7 \%(1)$ & $12.7 \%(7)$ & $5.0 \%$ & 2.28 & $.025 *$ \\
\hline Oficios & $25.0 \%(7)$ & $47.9 \%(23)$ & $22.9 \%$ & 5.42 & $<.000^{* *}$ \\
\hline Tareas domésticas & $4.4 \%(4)$ & $14.0 \%(7)$ & $9.6 \%$ & 3.24 & $.002^{* *}$ \\
\hline Transporte & $96.1 \%(148)$ & $72.3 \%(68)$ & $-23.8 \%$ & 5.56 & $<.000^{* *}$ \\
\hline
\end{tabular}

Fuente: Elaboración propia.

En lo que respecta a la representación única de niñas, se observa que solamente en dos tipos no hay cambios significativos entre años: aire libre y científicos, así como en bélicos donde se mantiene el $0 \%$ de presencia de niñas. Siendo el resto significativo, cabe destacar, los incrementos que se producen en los tipos construcción (17.7\%) y transporte $(15.4 \%)(\mathrm{p}<.001)$ y los descensos en tareas domésticas $(-50.9 \%)$, musicales (-31.0\%), oficios (-28.9\%) y juegos de interior activos (-27.5\%). 
TABLA 2

ANÁLISIS COMPARATIVO DE LA PRESENCIA DEL GÉNERO FEMENINO EN CADA TIPO DE JUGUETE

\begin{tabular}{|c|c|c|c|c|c|}
\hline \multirow{2}{*}{ TIPO } & \multicolumn{2}{|c|}{ \% NIÑAS / AÑO } & \multirow{2}{*}{$\begin{array}{l}\text { VARIACIÓN } \\
\text { PORCENTUAL }\end{array}$} & \multicolumn{2}{|c|}{ TEST BINOMIAL } \\
\hline & 2012 & 2015 & & VALOR & $p$ \\
\hline Aire libre & $3.8 \%(1)$ & $6.1 \%(3)$ & $2.3 \%$ & 1.53 & .130 \\
\hline Bélicos & 0 & 0 & 0 & -- & -- \\
\hline Científicos & $24.0 \%(6)$ & $25.5 \%(12)$ & $1.5 \%$ & 1.23 & .222 \\
\hline Construcción & $9.1 \%(2)$ & $26.8 \%(22)$ & $17.7 \%$ & 4.61 & $<.000^{* *}$ \\
\hline Deportes & $28.6 \%(4)$ & $41.4 \%(12)$ & $12.8 \%$ & 3.81 & $<.000^{* *}$ \\
\hline Estética & $100 \%(19)$ & $76.0 \%(19)$ & $-24.0 \%$ & 5.59 & $<.000^{* *}$ \\
\hline Figuras acción & $32.0 \%(8)$ & $10.0 \%(4)$ & $-22.0 \%$ & 5.28 & $<.000^{* *}$ \\
\hline $\begin{array}{c}\text { Juegos de interior } \\
\text { activos }\end{array}$ & $46.7 \%(14)$ & $19.2 \%(14)$ & $-27.5 \%$ & 6.13 & $<.000^{* *}$ \\
\hline Juegos de mesa & $32.8 \%(22)$ & $23.7 \%(14)$ & $-9.1 \%$ & 3.15 & $.002^{* *}$ \\
\hline Manualidades/arte & $50.6 \%(45)$ & $36.4 \%(8)$ & $-14.2 \%$ & 4.05 & $<.000^{* *}$ \\
\hline $\begin{array}{l}\text { Medios de } \\
\text { locomoción }\end{array}$ & $26.6 \%(71)$ & $20.1 \%(47)$ & $-6.5 \%$ & 2.62 & $.010^{*}$ \\
\hline Muñecas/peluches & $96.9 \%(154)$ & $80.6 \%(104)$ & $-16.3 \%$ & 4.39 & $<.000^{* *}$ \\
\hline Musicales & $54.1 \%(20)$ & $23.1 \%(9)$ & $-31.0 \%$ & 6.67 & $<.000^{* *}$ \\
\hline Nuevas tecnologías & $37.8 \%(14)$ & $50.0 \%(3)$ & $12.2 \%$ & 3.71 & $<.000^{* *}$ \\
\hline Objetos cotidianos & $46.2 \%(6)$ & $27.3 \%(15)$ & $-18.9 \%$ & 4.80 & $<.000^{* *}$ \\
\hline Oficios & $64.3 \%(18)$ & $35.4 \%(17)$ & $-28.9 \%$ & 6.34 & $<.000^{* *}$ \\
\hline Tareas domésticas & $78.9 \%(71)$ & $28.0 \%(14)$ & $-50.9 \%$ & 10.13 & $<.000^{* *}$ \\
\hline Transporte & $0.6 \%$ (1) & $16.0 \%(15)$ & $15.4 \%$ & 4.24 & $<.000^{* *}$ \\
\hline$p<.05$ & & & & & \\
\hline
\end{tabular}

Fuente: Elaboración propia.

Por último, en los anuncios con aparición de ambos sexos no se han producido cambios significativos en aire libre, bélicos, juegos de interior activos y nuevas tecnologías. No obstante, se dan cambios, que implican un aumento de anuncios mixtos en 2015, en la mayoría de los tipos de juguetes. Cabe destacar los importantes incrementos en categorías como tareas domésticas (41.3\%), manualidades/arte (38.8\%) y juegos de mesa (30.1\%). Por el contrario, se aprecia un sensible descenso de anuncios mixtos en deportes (-43.1\%) y construcción (-15.4\%). 
TABLA 3

ANÁLISIS COMPARATIVO DE LA PRESENCIA DEL GÉNERO MIXTO EN CADA TIPO DE JUGUETE

\begin{tabular}{|c|c|c|c|c|c|}
\hline \multirow{2}{*}{ TIPO } & \multicolumn{2}{|c|}{ \% MIXTO / AÑO } & \multirow{2}{*}{$\begin{array}{l}\text { VARIACIÓN } \\
\text { PORCENTUAL }\end{array}$} & \multicolumn{2}{|c|}{ TEST BINOMIAL } \\
\hline & 2012 & 2015 & & VALOR & $P$ \\
\hline Aire libre & $84.6 \%(22)$ & $87.8 \%(43)$ & $3.2 \%$ & 1.81 & .073 \\
\hline Bélicos & $4.2 \%(1)$ & $6.3 \%(1)$ & $2.1 \%$ & 1.46 & .148 \\
\hline Científicos & $16.0 \%(4)$ & $27.7 \%(13)$ & $11.7 \%$ & 3.62 & $<.000^{* *}$ \\
\hline Construcción & $22.7 \%(5)$ & $7.3 \%(6)$ & $-15.4 \%$ & 4.24 & $<.000^{* *}$ \\
\hline Deportes & $50.0 \%(7)$ & $6.9 \%(2)$ & $-43.1 \%$ & 8.66 & $<.000^{* *}$ \\
\hline Estética & 0 & $20.0 \%(5)$ & $20.0 \%$ & 4.98 & $<.000^{* *}$ \\
\hline Figuras acción & $8.0 \%(2)$ & $25.0 \%(10)$ & $17.0 \%$ & 4.50 & $<.000^{* *}$ \\
\hline $\begin{array}{c}\text { Juegos de interior } \\
\text { activos }\end{array}$ & $16.7 \%(5)$ & $19.2 \%(14)$ & $2.5 \%$ & 1.59 & .114 \\
\hline Juegos de mesa & $34.3 \%$ (23) & $64.4 \%$ (38) & $30.1 \%$ & 6.53 & $<.000^{* *}$ \\
\hline Manualidades/arte & $15.7 \%(14)$ & $54.5 \%(12)$ & $38.8 \%$ & 7.92 & $<.000^{* *}$ \\
\hline $\begin{array}{l}\text { Medios de } \\
\text { locomoción }\end{array}$ & $2.6 \%(7)$ & $24.8 \%(58)$ & $22.2 \%$ & 5.32 & $<.000^{* *}$ \\
\hline Muñecas/peluches & $0.6 \%(1)$ & $7.8 \%(10)$ & $7.2 \%$ & 2.77 & $.007^{* *}$ \\
\hline Musicales & $8.1 \%(3)$ & $12.8 \%(5)$ & $4.7 \%$ & 2.21 & $.029 *$ \\
\hline Nuevas tecnologías & $13.5 \%(5)$ & $16.7 \%(1)$ & $3.2 \%$ & 1.81 & .073 \\
\hline Objetos cotidianos & $46.2 \%(6)$ & $60.0 \%$ (33) & $13.8 \%$ & 3.98 & $<.000^{* *}$ \\
\hline Oficios & $10.7 \%(3)$ & $16.7 \%(8)$ & $6.0 \%$ & 2.51 & $.014^{*}$ \\
\hline Tareas domésticas & $16.7 \%(15)$ & $58.0 \%$ (29) & $41.3 \%$ & 8.35 & $<.000^{* *}$ \\
\hline Transporte & $3.2 \%(5)$ & $11.7 \%$ (11) & $8.5 \%$ & 3.03 & $.003^{* *}$ \\
\hline
\end{tabular}

Fuente: Elaboración propia.

El Gráfico 1 resume las variaciones de los tres tipos de representación analizados en todas las categorías de juguetes, mostrando los valores positivos que indican un aumento en 2015 y los negativos, indicativos de un descenso. Los cambios más extremos se han presentado en deporte, manualidades/arte y tareas del hogar. 


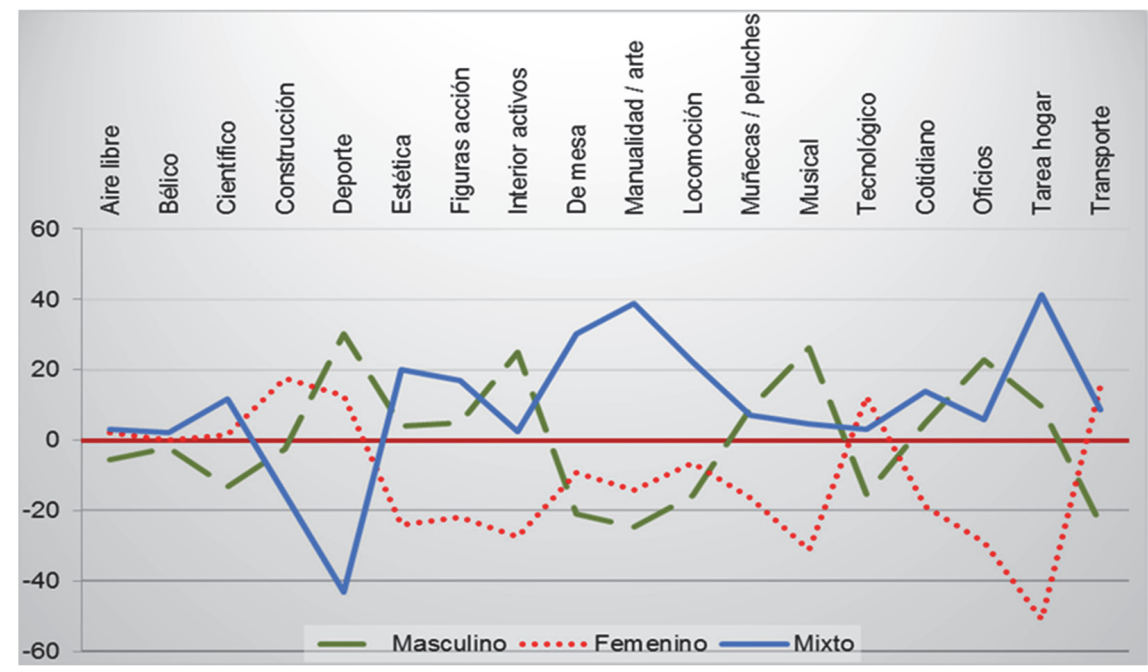

Fuente: Elaboración propia.

\section{RESULTADOS DE LOS DATOS CUALITATIVOS}

El análisis cualitativo nos permite profundizar en los roles y valores que transmiten las imágenes analizadas, aportando fundamentos complementarios para su evaluación. Cuando las niñas se muestran como modelos en categorías clásicas femeninas representan simbólicamente el mundo de los cuidados, la preocupación por la apariencia y actividades en el espacio privado, reproduciendo estereotipos de género tradicionales. Por otra parte, los escenarios de aventura, acción y agresividad son representados por niños.

En las imágenes mixtas, el rol de género difiere en varias categorías. Así, en medios de locomoción, ellos aparecen como pilotos y ellas como acompañantes. Además, se ha observado en juguetes de tareas del hogar al varón con una función de mero espectador, situación que no se da a la inversa. En la misma línea, percibimos en otras categorías algunos ejemplos en los que son los niños los que actúan y ellas las que simplemente observan cómo juegan ellos. Sin embargo, en aire libre no se aprecia a las niñas en actitudes pasivas; aunque hay excepciones, en general, ellas disfrutan de la acción lúdica y manipulan objetos, se desplazan, etc.

Si atendemos a criterios como el de la complejidad del producto y de las acciones que favorece, el análisis aporta elementos muy interesantes para la construcción de identidades. De esta forma, en los medios de locomoción, la mayoría de niñas aparecen en triciclos o bicicletas, pero rara vez en vehículos que puedan guardar similitud con los utilizados por las personas adultas, como ocurre en el caso de los niños. Respecto a los juguetes de construcción observamos 
mayor elaboración cuando se trata de construcciones para niños en comparación con la sencillez de algunas representadas por niñas.

Cuando los juguetes se vinculan a profesiones, donde el personaje aparece disfrazado o con alguna prenda que le identifica con un oficio, ellas ejercen principalmente de veterinarias, médicas, peluqueras, camareras, tenderas, maquilladoras, costureras o diseñadoras de moda. A su vez, ellos suelen ser carpinteros, jefes de obra, chefs, pilotos de carreras de coches o motos. Del mismo modo, cuando aparecen profesionales del ámbito sanitario o gastronómico, los roles que se plasman son bastante distintos, vinculando la figura femenina a posiciones tradicionales, que en muchas ocasiones implican menor categoría profesional. Por ejemplo, cuando las niñas aparecen en las fotos de anuncios de cocinas no aparecen con un traje de chef, sino con un delantal que las ubica en un contexto doméstico, de ama de casa, mientras ellos sí aparecen uniformados, haciendo referencia a un espacio profesional o público.

En cuanto a los personajes de ficción, los héroes o superhéroes son para niños y los gatitos, las princesas o las figuras femeninas de series de televisión para niñas. Para ellos se transmite una idea más cercana al arquetipo de guerrero u hombre protector, como Spiderman o personajes masculinos de Star Wars; y para ellas valores ligados a la ternura y la estética, que representan Violetta o las princesas de Disney.

Por último, el color rosa es exclusivo para las féminas, fundamentalmente en la categoría muñecas/peluches. Excepcionalmente, hemos encontrado alguna foto en la que un niño aparece ligado a este color, bien respecto al fondo de página, bien al producto. Este vínculo niña-rosa es más fuerte que el de niño-azul. Es muy frecuente, además, ante la promoción de un mismo producto, que este sea rosa si lo presenta una niña y de otro color si lo hace un niño. Del mismo modo, se recurre al azul cuando en la categoría muñecas/peluches aparecen niños. En general, para ellos se utilizan más variedad de colores. Los catálogos de juguetes educativos también se ven influenciados por estos estereotipos, ya que utilizan el rosa o colores pastel para juguetes asociados tradicionalmente a niñas.

\section{DISCUSIÓN}

Este trabajo se centraba en estudiar qué tipo de representación infantil, teniendo en cuenta el sexo, se ofrece desde las imágenes de los juguetes de los catálogos publicitarios, examinando si existe alguna evolución al comparar las navidades de 2012 y 2015.

El número total de imágenes de representación única de varones apenas ha variado, siendo la de mayor proporción en ambos períodos; sin embargo, la presencia exclusiva de niñas disminuye en el 2015 y es la mixta la que aumenta. 
Una parte sustancial de las imágenes transmite de forma notoria estereotipos tradicionales de masculinidad y feminidad. En lo que respecta a la representación de las niñas, dos categorías de juguetes asociadas habitualmente a ellas, como son muñecas/peluches y estética, siguen apareciendo mayoritariamente como propias de lo femenino. Por su parte, los niños siguen siendo protagonistas en tipologías clásicas como juguetes bélicos, construcción, figuras de acción, medios de locomoción o transporte. Esto mismo se puede apreciar en otros estudios precedentes (AUSTER; MANSBACH, 2012; MARTÍNEZ-PASTOR; NICOLÁS; SALAS, 2013; PEREIRA, 2009). También las habilidades y roles que fomentan son distintos, tal y como se constató a raíz del análisis cualitativo. Coincidimos con las reflexiones aportadas por Espinar (2007) sobre la actividad masculina y la pasividad femenina que muestra la publicidad. Asimismo, apreciamos valores unidos a lo fashion y maternal para las mujeres frente a valores de violencia simbólica, poder y fuerza para hombres (BLAKEMORE; CENTERS, 2005; FERRER, 2007; PEREIRA, 2009; PÉREZ-UGENA; MARTÍNEZ-PASTOR; SALAS, 2011).

En cuanto a los colores, se constataron las tendencias reflejadas en otros trabajos como el de Auster y Mansbach (2012), Ferrer (2007) o Pereira (2009). En relación con este tema Weisgram, Fulcher y Dinella (2014) demuestran el gran impacto del color en la selección de juguetes, mientras Wong y Hines (2015) ponen de manifiesto la necesidad de eliminar este código de género para propiciar mayor igualdad de oportunidades en el aprendizaje.

En categorías vinculadas con la actividad física, como la de deportes, medios de locomoción o juegos de interior activos, se observó más asociación de imágenes masculinas a valores como la competencia, el desarrollo físico o las habilidades, en consonancia con estudios como el de Martínez-Pastor, Nicolás y Salas, (2013) o Pérez-Ugena, MartínezPastor y Salas (2011).

Desde otra perspectiva argumentativa, queremos subrayar ciertas cuestiones que se pueden leer en clave de cambio. Así como los juguetes bélicos siguen ofertándose claramente como patrimonio de lo masculino, la representación de niñas en construcción o transportes aumentó significativamente en el 2015. También los juguetes científicos disminuyen en las imágenes de niños y subieron en las mixtas. Este tipo de productos, catalogados como masculinos en estudios como el de Miller (1987), pasaron posteriormente a tener una tendencia algo más neutra (BLAKEMORE; CENTERS, 2005) y esto se refleja también en nuestros datos, de manera que tampoco se promocionan como exclusivamente para varones. En la actualidad, también el alumnado categoriza juguetes como la maleta de médico/a o el microscopio como mixtos; esto es, que no son exclusivos de niños o de niñas (MORINMESSABEL et al., 2016). 
Igualmente, en los juguetes tecnológicos se observó un descenso en niños y un aumento en niñas, de manera que se rompen tendencias antiguas que los vinculaban solo a lo masculino, algo ya constatado por el Consejo Audiovisual de Andalucía en 2009.

En las categorías muñecas/peluches y estética, se observó algo similar a lo encontrado respecto a juguetes típicamente masculinos; pese a ser tipologías en las que una gran parte de las fotos mostraban solo al sexo femenino, se detectaron aumentos significativos en la representación de niños y mixta y descensos significativos en niñas. Además, en la categoría tareas del hogar encontramos datos llamativos, que se diferencian de lo aportado tanto en la literatura de hace décadas (MILLER, 1987; RHEINGOLD; COOK, 1975) como en la más reciente (AUSTER; MANSBACH, 2012; BLAKEMORE; CENTERS, 2005; MARTÍNEZPASTOR; NICOLÁS; SALAS, 2013; PÉREZ-UGENA; MARTÍNEZ-PASTOR; SALAS, 2011). Al comparar los dos períodos navideños, observamos que este tipo de juguetes, con representación mayoritaria de niñas en 2012 , han pasado a ser predominantemente mixtos.

Por otra parte, al examinar los resultados relativos a tipologías de tendencia más neutra, apreciamos respecto a los juguetes musicales un importante incremento en imágenes de niños y una importante bajada en las de niñas, de manera que se pueden situar, al igual que en el estudio de Auster y Mansbach (2012) en una esfera más masculina. Esto difiere de otras aportaciones como las de Rheingold y Cook (1975) o Blakemore y Centers (2005) en las que se consideran más neutrales. Algo similar sucedió con los juguetes asociados a oficios y de interior activos, que pasaron de ser representados principalmente por el sexo femenino a hacerlo en su mayor parte por el masculino. En estos tres casos, la proporción de imágenes mixtas fue siempre baja en ambos períodos de estudio. La categoría manualidades/arte experimentó también cambios interesantes, pasando de ser un producto de tendencia femenina a neutra, algo que coincide con estudios como los de Miller (1987) o Blakemore y Centers (2005). Finalmente, en juegos de mesa y objetos cotidianos se observó también una variación sustancial hacia la representación mixta.

Si hablamos de cantidad, la evolución se ve más fácilmente que si hablamos de calidad. En efecto, muchos de los avances encontrados se ven ensombrecidos con los elementos de la evaluación cualitativa. En bastantes fotos mixtas, pese a mostrar figuras femeninas y masculinas en el mismo escenario, el principio de equidad es cuestionable. Percibimos que mientras las sociedades avanzan y la investigación considera que existen diferentes tipos de masculinidades y feminidades, la publicidad infantil no ha evolucionado en el mismo sentido.

Nos unimos a la crítica recogida al principio del documento relativa a la falta de cumplimiento de la legislación vigente; las campañas 
publicitarias deben contribuir a hacer una sociedad más responsable, difundiendo mensajes más inclusivos.

A esto hay que añadir el importante papel de la escuela en la educación a través de los medios. El análisis y la crítica razonada a partir del uso de estos recursos construyen género y pueden ayudar al cambio de mentalidad y de conducta (ROCA et al., 2008). En este sentido, entendemos que este artículo puede aportar elementos de reflexión para el profesorado en formación o en activo. Además, no se puede olvidar el inmenso potencial de la escuela para utilizar medios lúdicos ricos y variados que desarrollen competencias artísticas, de lógica, de creación, etc. (MORIN-MESSABEL et al., 2016), independientemente del sexo del sujeto.

Se podría considerar como límite de la investigación el hecho de que la selección de la muestra de catálogos sea de conveniencia, aunque consideramos que su número es importante y que representa a las empresas jugueteras de máxima influencia en España.

Como líneas de estudio futuras destacamos el abordaje de esta materia en las redes sociales. Dentro del ámbito educativo también sería interesante investigar si los cambios en los catálogos permiten nuevas lecturas de la publicidad en el aula. También se puede observar si en los años venideros las tendencias en los catálogos infantiles son más equitativas. Queremos creer que este sea el principio de ese camino y que pronto se dé un importante salto cualitativo en este sentido.

\section{CONCLUSIONES}

Los hallazgos encontrados se pueden interpretar como una pequeña evolución en el tema que nos ocupa. La representación única de varones es mayor que la de niñas y la mixta y apenas ha variado en ambos períodos. Se siguen reproduciendo estereotipos asociados a roles tradicionales de género y a los colores.

No obstante, existe un importante incremento de imágenes mixtas en las que niñas y niños comparten actividades. Entendemos que se están rompiendo barreras lentamente, tomando como base la desigualdad histórica que hay en el mundo de los juguetes, pero que hay ciertos espacios que no han sido derribados, ya que los avances se han dado solo en algunas categorías de análisis.

El reto futuro ha de ir más allá de mostrar a niños y niñas en torno a una misma actividad. La clave está en vender imágenes de justicia en la igualdad. Por ello, sería muy conveniente que en próximas investigaciones se planteara el análisis profundo de los valores que las imágenes mixtas transmiten. 


\section{REFERENCIAS}

ASOCIACIÓN ESPAÑOLA DE FABRICANTES DE JUGUETES. Código de autorregulación de la publicidad infantil de juguetes. Madrid, 2010.

AUSTER, Carol J.; MANSBACH, Claire S. The gender marketing of toys: an analysis of color and type of toy on the Disney store website. Sex Roles, Lancaster, v. 67, n. 7-8, p. 375-388, 2012.

BLAKEMORE, Judith E.; CENTERS, Renee E. Characteristics of boys' and girls' toys. Sex Roles, Lancaster, v. 53, n. 10-11, p. 619-633, 2005.

BRINGUÉ, Xabier; DE LOS ÁNGELES, Juan. La investigación académica sobre publicidad, televisión y niños: antecedentes y estado de la cuestión. Comunicación y Sociedad, Navarra, v. 13, n. 1, p. 37-70, 2000.

CHERNEY, Isabelle D. et al. The effects of stereotyped toys and gender on play assessment in children aged 18-47 months. Educational Psychology, Omaha, v. 23, n. 1, p. 95-106, 2003.

CHERNEY, Isabelle D.; DEMPSEY, Jessica. Young children's classification, stereotyping and play behaviour for gender neutral and ambiguous toys. Educational Psychology, Omaha, v. 30, n. 6, p. 651-669, 2010.

CHERNEY, Isabelle D.; LONDON, Kamala. Gender-linked differences in the toys, television shows, computer games, and outdoor activities of 5-to 13-year-old children. Sex Roles, Lancaster, v. 54, n. 9-10, p. 717-726, 2006.

CORSARO, William A. Interpretive reproduction in children's role play. Childhood, Thousand Oaks, v. 1, n. 2, p. 64-74, 1993.

CORSARO, William A. The sociology of childhood. Thousand Oaks, CA: Pine Forge, 2005.

CUGMAS, Zlatka. Igra s spolno stereotipnimi igra®ami. Didactica Slovenica - Pedagoška Obzorja, v. 25, n. 3-4, p. 130-146, 2010.

DOWNS, A. Chris. Letters to Santa Claus: elementary school-age children's sex-typed toy preferences in a natural setting. Sex Roles, Lancaster, v. 9, n. 2, p. 159-163, 1983.

ESPAÑA. Consejo Audiovisual de Andalucía. Estudio sobre la publicidad de juguetes en la campaña de Navidad 2008-2009. Sevilla, 2009.

ESPAÑA. Ley 34, de 11 de noviembre de 1988. General de la publicidad. BOE, 274, de 15 de noviembre, 32464-32467. Madrid, 1988.

ESPAÑA. Ley Orgánica 1, de 28 de diciembre de 2004. Medidas de protección integral contra la violencia de género. BOE, 313, de 29 de diciembre, 42166-42197. Madrid, 2004.

ESPAÑA. Ley Orgánica 3, de 22 de marzo de 2007. Igualdad efectiva de mujeres y hombres. BOE, 71, de 23 de marzo, 12611-12645. Madrid, 2007.

ESPAÑA. Ley 34, de 11 de noviembre de 1988. General de la publicidad. BOE, 274, de 15 de noviembre, 32464-32467. Modificación de 28 de marzo de 2014. Madrid, 2014.

ESPINAR, Eva. Estereotipos de género en los contenidos audiovisuales infantiles: gender stereotypes in audiovisual products for children. Comunicar, Huelva, v. 15, n. 29, p. 129-134, 2007.

FERRER, Marina. Los anuncios de juguetes en la campaña de Navidad: content analysis about toy's advertisment during Christmas campaign. Comunicar, Huelva, v. 15, n. 29, p. 135-142, 2007.

FISHER-THOMPSON, Donna. Adult sex typing of children's toys. Sex Roles, Lancaster, v. 23, n. 5-6, p. 291-303, 1990.

FISHER-THOMPSON, Donna; SAUSA, Angela D.; WRIGHT, Terry F. Toy selection for children: personality and toy request influences. Sex Roles, Lancaster, v. 33, n. 3-4, p. 239-255, 1995.

FRANCIS, Becky. Gender, toys and learning. Oxford Review of Education, London, v. 36, n. 3, p. 325-344, 2010. 
JADVA, Vasanti; HINES, Melissa; GOLOMBOK, Susan. Infants' preferences for toys, colors, and shapes: sex differences and similarities. Archives of Sexual Behavior, Cambridge, v. 39, n. 6 , p. 1261-1273, 2010.

KAHLENBERG, Susan G.; HEIN, Michelle M. Progression on Nickelodeon? Gender-role stereotypes in toy commercials. Sex Roles, Lancaster, v. 62, n. 11-12, p. 830-847, 2010.

LÓPEZ-VILLAR, Cristina. Masculinidades lúdicas. La construcción de identidades masculinas desde la publicidad infantil. In: PIEDRA, Joaquín (Org.). Géneros, masculinidades y diversidad. Educación física, deporte e identidades masculinas. Granada: Octaedro, 2013. p. 100-130.

MARCON, Rebeca A.; FREEMAN, George. Linking gender-related toy preferences to social structure: changes in children's letters to Santa since 1978. Journal of Psychological Practice, Savannah, v. 2, n. 1-10, p. 1-9, 1996.

MARTÍNEZ-PASTOR, ESTHER; NICOLÁS, M. ÁNGEL; SALAS, ÁLVARO. La representación de género en las campañas de publicidad de juguetes en Navidades (2009-12). Comunicar, Huelva, v. 21, n. 41, p. 187-194, 2013.

MARTÍNEZ-REINA, María del Carmen; VÉLEZ, Manuel. Actitud en niños y adultos sobre los estereotipos de género en juguetes infantiles. Ciencia Ergo Sum, Toluca, v. 16, n. 2, p. 137-144, jul./oct. 2008.

MILLER, Cynthia L. Qualitative differences among gender-stereotyped toys: implications for cognitive and social development in girls and boys. Sex Roles, Lancaster, v. 16, n. 9, p. 473-487, 1987.

MORIN-MESSABEL, Christine et al. Representações das categorias de sexo em crianças no contexto escolar. Cadernos de Pesquisa, São Paulo, v. 46, n. 160, p. 526-546, abr./jun. 2016.

NELSON, Anders. Children's toy collections in Sweden - a less gender-typed country? Sex Roles, Lancaster, v. 52, n. 1-2, p. 93-102, 2005.

PEREIRA, Carmen. La publicidad de los juguetes. Una reflexión sobre sus contravalores y sobre el fomento de la desigualdad de género. Ricerche di Pedagogia e Didattica, Bologna, v. 4, n. 2, p. 1-14, 2009.

PÉREZ-UGENA, Álvaro; MARTÍNEZ-PASTOR, Esther; SALAS, Álvaro. Los estereotipos de género en la publicidad de los juguetes. Ámbitos, Sevilla, n. 20, p. 217-235, 2011.

PINE, Karen J.; WILSON, Penny; NASH, Avril S. The relationship between television advertising, children's viewing and their requests to Father Christmas. Journal of Developmental \& Behavioral Pediatrics, Philadelphia, v. 28, n. 6, p. 456-461, 2007.

PINO-JUSTE, Margarita. La influencia de los medios de comunicación social en la infancia. Pedagogía Social: Revista Interuniversitaria, Salamanca, n. 5, p. 233-243, 2000.

POMERLEAU, Andrée. Pink or blue: environmental gender stereotypes in the first two years of life. Sex Roles, Lancaster, v. 22, n. 5-6, p. 359-367, 1990.

RHEINGOLD, Harriet. L.; COOK, Kaye V. The contents of boys' and girls' rooms as an index of parents' behavior. Child Development, Malden, v. 46, n. 2, p. 459-463, 1975.

ROCA, María et al. ¡Todos para uno y uno para todos! Cuadernos de Pedagogía, Pontevedra, n. 376, p. 32-35, 2008.

STEINBERG, Shirley R.; KINCHELOE, Joe L. Kinderculture: the corporate construction of childhood. Boulder, CO: Westview, 1997.

TOBIN, Desiree D. et al. The intrapsychics of gender: a model of self-socialization. Psychological Review, v. 117, n. 2, p. 601-622, 2010.

TODD, Brenda K; BARRY, John A.; THOMMESSEN, Sara A. O. Preferences for 'gender-typed' toys in boys and girls aged 9 to 32 months. Infant and Child Development, 2016. DOI: 10.1002/icd.1986

WEISGRAM, Erica S.; FULCHER, Megan; DINELLA, Lisa M. Pink gives girls permission: exploring the roles of explicit gender labels and gender-typed colors on preschool children's toy preferences. Journal of Applied Developmental Psychology, v. 35, n. 5, p. 401-409, 2014. 
WONG, Wang I.; HINES, Melissa. Effects of gender color-coding on toddlers' gender-typical toy play. Archives of Sexual Behavior, New York, v. 44, n. 5, p. 1.233-1.242, 2015.

ZEGAÏ, Mona. La mise en scène de la différence des sexes dans les jouets et leurs espaces de commercialisation. Cahiers du Genre, Paris, n. 49, p. 35-54, 2010. 